\title{
Vestibulares vídeo-gravados em libras: um novo modo de acesso ao ensino superior federal?
}

\author{
Luiz Renato Martins Rocha* \\ Cristina Broglia Feitosa Lacerda**
}

\section{Resumo}

O direito da pessoa surda à escolarização tem, ao longo das últimas duas décadas, impactado fortemente no crescimento de seu acesso ao ensino superior, antes restrito a uma pequena parcela da população. A vídeo-gravação de alguns vestibulares em Libras foi uma resposta às demandas da comunidade surda, que almeja a valorização de sua participação no meio acadêmico. $\mathrm{O}$ objetivo principal deste estudo foi investigar como os surdos que prestaram os vestibulares vídeo-gravados em Libras de duas universidades federais públicas, perceberam o atendimento às suas necessidades linguísticas. Para alcançar tal objetivo, lançamos máo da pesquisa qualitativa de natureza exploratória e descritiva e entrevista semiestruturada. Todas as entrevistas foram traduzidas e categorizadas, identificando divergências e convergências presentes nos depoimentos. Os resultados nos mostram que os surdos ficaram satisfeitos com a vídeo-gravação da prova em Libras de ambas às universidades, e apontaram possíveis ajustes a serem feitos no sentido de melhorar ainda mais esse tipo de prova. Porém, o ingresso efetivo de surdos nas universidades brasileiras é baixo, indicando a necessidade de lutar pela melhoria da educação básica para uma preparação mais efetiva desses alunos, atendendo assim, suas necessidades linguísticas, culturais e pedagógicas.

Palavras-chave: Vestibular em libras; Ensino superior; Tradução e interpretação em libras; Educaçáo de surdos; Educação especial.

\footnotetext{
* Doutorando em Educação Especial pela Universidade Federal de São Carlos, São Carlos, São Paulo, Brasil.
}

** Professora doutora da Universidade Federal de São Carlos, São Carlos, São Paulo, Brasil. 


\section{Video recorded entrance examinations in libras: new way to access the federal university?}

\section{Abstract}

Over the last two decades, deaf people's rights to schooling has strongly impacted the increasing of their access to the university, once restricted to a small portion of population. Video recording some entrance examinations in Libras (Brazilian Sign Language) was a response to the deaf community demand, which wants the valorization of their contributions for the scientific community. In this study, we aimed to investigate: How did deaf people take the video recorded entrance examinations in Libras for two federal public universities? And how did they understand the service addressed to meet their language needs? We carried out a qualitative research, exploratory and descriptive, with a semi-structured interview. We translated and categorized all the interviews, identifying divergences and convergences within the statements. The results show that deaf people were satisfied with the video recorded entrance examination in Libras in both universities. They also pointed out some potential adjustments to further improve this kind of exam. However, the effective entrance of deaf people in Brazilian universities is considered low, suggesting the need to strive for an improvement on the basic education in order to prepare those students and meet their language, cultural and educational needs.

Keywords: Entrance examination in libras; Higher education; Libras translation and interpretation; Deaf education; Special education.

\section{Introdução}

O ensino superior no Brasil vem, ao longo das últimas duas décadas, crescendo consideravelmente, o que consequentemente elevou o número de matrículas a recordes históricos antes não alcançados na educação brasileira, entre outros fatores, tal crescimento têm como importantes propulsores a "Lei de Diretrizes e Bases da Educação Nacional (LDB), Lei no 9.394/96; o Plano Nacional de Educaçáo (PNE), Lei ${ }^{\circ} 10.172 / 01$, e, mais recentemente, a Lei 13.005/2014 - com o novo PNE" (ROCHA, 2015, p. 15) entre outros, que, têm favorecido a elevação do número de pessoas sem e com deficiência nas instituiçôes de ensino superior (IES).

O número de matrículas no ensino superior no Brasil cresceu, em dez anos, aproximadamente 86\% (MEC, 2013ㄹ), passando de 3.936.933 matrículas em 2003 para 7.305.977 de matrículas em 2013. Esse aumento significativo também foi sentido no número de matrículas das pessoas com deficiência (crescimento exponencial) nesse nível de ensino, antes restrito basicamente à elite e às pessoas sem deficiência.

Nos últimos dez anos, as matrículas das pessoas com deficiência passaram de 5.078 para 29.737 , um aumento de aproximadamente $485 \%$, ou seja, enquanto a população no ensino superior de pessoas sem deficiência cresceu cerca de $86 \%$ no período de 2003 a 2013, o ingresso das pessoas com deficiência nessa mesma modalidade teve um aumento aproximadamente 5,5 vezes maior que as sem deficiência (MEC, 2013). 
Com relação às pessoas surdas, foco do presente estudo, os números nos mostram que havia, em 2003, no ensino superior, zero surdos ${ }^{2}$ matriculados e 344 deficientes auditivos ${ }^{3}$; já em 2013, havia 1.488 surdos e 7.037 deficientes auditivos, um aumento de surdos e deficientes auditivos de aproximadamente $1478 \%$ no número de matrículas (MEC, 2013). Logo, esses números nos revelam, que o acesso de pessoas surdas e de deficientes auditivos cresceu mais do que o das pessoas com deficiência no geral (três vezes maior) e ainda mais, quando comparado com o das pessoas sem deficiência (17 vezes maior).

No campo da surdez, as políticas públicas - que, diga-se de passagem, são bastante recentes (boa parte tem menos de 15 anos de existência) -, aos poucos começam a transformar um cenário exclusivamente dedicado a levar o deficiente auditivo a ouvir (oralista) em espaços que contemplem, mesmo que de forma mínima, a Língua de Sinais (acessível aos surdos) - abrindo a perspectiva de criaçáo de espaços sociais bilíngues.

Assim, a língua dos surdos, que historicamente foi marginalizada, começa a adentrar os espaços acadêmicos. Além dessa língua estar presente em algumas salas de aula, pela presença obrigatória do intérprete de Libras (Língua Brasileira de Sinais) (BRASIL, 2005), é possível encontrar alguns exames vestibulares, que tradicionalmente eram realizados somente em Língua Portuguesa escrita, serem ofertados também em Libras. Em 2010, a Universidade Federal de Santa Maria (UFSM) e 2013 a Universidade Federal de Santa Catarina (UFSC), a contar com a tradução em formato vídeo-gravado em Libras.

Outras Universidades também realizaram a vídeo-gravação em Libras de seus vestibulares, porém, interromperam estes, no ano seguinte a traduçáo, sendo estas: Universidade Federal de Grande Dourados (2010), Universidade Federal da Paraíba (2012) - tradução apenas da prova de Língua Portuguesa e Universidade Estadual de Londrina (2011).

A presença da língua de sinais no ensino superior se dá em função de legislação que impulsiou o respeito pela singularidade linguística da pessoa surda, a saber:

a) Declaração de Salamanca (1994): grande impulsionador das políticas inclusivas no Brasil e no mundo, que estabelece, entre várias medidas, o direito da pessoa com deficiência à escola.

b) Aviso Circular no 277/1996: tal documento é encaminhado pelo MEC às IES (destinado especificamente aos reitores destas) com recomendaçóes quanto ao atendimento dos "portadores de necessidades especiais"4 quando inscritos no processo de seleção à IES, dividido em três momentos específicos, a saber: na elaboraçáo do edital, no momento da aplicação dos exames e no momento da correção das provas. Para as pessoas surdas, esclarece que deve haver nas avaliaçóes a presença de um intérprete de Libras; flexibilização na correção das redaçôes e provas dos surdos. 
c) Lei 10.436/2002: Grande conquista da comunidade surda, pois reconhece em âmbito nacional a Língua Brasileira de Sinais (Libras) como meio de comunicação e expressão. Porém, vale ressaltar que, no artigo $4^{\circ}$, parágrafo único, é explicitado que: "a Língua Brasileira de Sinais - Libras não poderá substituir a modalidade escrita da língua portuguesa”, deixando clara a necessidade de ensino da Língua Portuguesa aos surdos. ${ }^{5}$

d) Portaria $n^{\circ} 3.284 / 2003$ : Esta portaria dispóe sobre os requisitos de acessibilidade para as pessoas com deficiência nos processos de autorização e de reconhecimento de cursos superiores, e de credenciamento de instituiçóes, e assegura às pessoas com deficiência física e sensorial condiçôes básicas de acesso ao ensino superior, de mobilidade e de utilização de equipamentos e instalaçôes das IES. Para as pessoas surdas e deficientes auditivas, em suma a portaria recomenda que as IES devem propiciar: Intérpretes de Libras; Flexibilização na correção das provas; estimulo ao aprendizado da língua portuguesa pelos surdos e proporcionar aos professores, conhecimento linguístico das especificidades do sujeito surdo.

e) Decreto 5.626/2005: o decreto visa implementar a lei 10.436/2002, bem como regulamentá-la. O referido decreto, entre vários pontos, apresenta instrução às instituiçōes de ensino a "desenvolver e adotar mecanismos alternativos para a avaliaçâo de conhecimentos expressos em Libras, desde que devidamente registrados em vídeo ou em outros meios eletrônicos e tecnológicos" (BRASIL, 2005).

f) Recomendação 001/2010: emitida pelo Conselho Nacional dos Direitos da Pessoa com Deficiência (Conade), trata sobre a "aplicaçáo do princípio da acessibilidade à pessoa surda ou com deficiência auditiva em concursos públicos". $\mathrm{Na}$ presente recomendação, alguns princípios de acessibilidade são apontados quanto à forma de aplicação das provas às pessoas surdas, entre os quais: "As provas devem ser aplicadas em Língua Brasileira de Sinais - LIBRAS, com recursos visuais, por meio de vídeo ou outra tecnologia análoga, conforme as normas técnicas em vigor, disponibilizando, inclusive, intérprete habilitado para permitir o acesso ao conteúdo das provas" (BRASIL, 2010) e ainda, critérios específicos de correção das provas.

g) Lei 13.146/2015: legislação recente, conhecida também como o Estatuto da Pessoa com Deficiência e, entre várias observâncias, destacamos uma que nos é interessante citar, pois faz menção às pessoas surdas, obrigando as instituiçôes de ensino superior e de educação profissional e tecnológica, públicas e privadas, à: "adoção de critérios de avaliaçáo das provas escritas, discursivas ou de redação que considerem a singularidade linguística da pessoa com deficiência, no domínio da modalidade escrita da língua portuguesa" e "tradução completa do edital e de suas retificaçôes em Libras”. (BRASIL, 2015).

Tais políticas vêm ao encontro de uma defasagem vivenciada pelos surdos há séculos, inclusive nos dias de hoje, pois muitos nascem em lares que são desprovidos do conhecimento de sua língua, de sua história e de sua cultura, o que gera sérias consequências ao seu desenvolvimento linguístico-cognitivo. 
$\mathrm{Na}$ maioria dos casos, "pesquisas apontam que 95\% dos surdos nascem em lares [de famílias] ouvintes e que apenas uma pequena parcela, cerca de $5 \%$, nasce em lares em que pai e mãe são também surdos" (ROCHA, 2015, p. 46). Porém, quando essa língua não é acessível ao sujeito, de acordo com Vygotsky (2008), o desenvolvimento das funçóes psicológicas superiores (como: percepção, memória e atenção) sofrerá prejuízos.

Tal ausência de conhecimento e de oferta de condiçôes ideais geram a aquisição da linguagem tardia, levando a problemas na formaçấo de conceitos científicos, descritos por Vygotsky (2008) como aqueles que o sujeito aprende na escola, mais elaborados que os espontâneos (adquiridos nas relaçóes cotidianas, desde que o ambiente lhe seja propício). No entanto, quando a língua não é acessível, haverá falha no desenvolvimento da formação dos conceitos e, quando a pessoa ingressar na escola, "essas marcas ficam evidentes" (ROCHA, 2015, p. 47) e muitas vezes são perpetuadas durante todo o percurso acadêmico do sujeito surdo (LACERDA, 2013).

Nesse contexto de aquisição de linguagem tardia, somada à centralidade na oralidade estabelecida por grande parte das escolas, "temos (na educaçâo de surdos) uma apropriação precária da leitura e escrita, que impacta fortemente nos conhecimentos relacionados à língua portuguesa" (ROCHA, 2015, p. 48). Tais dificuldades com a Língua Portuguesa escrita dar-se-ão na leitura e interpretação de textos, já que a estrutura gramatical da Libras e de Língua Portuguesa são diferentes. Assim, comenta Fernandes que "os Surdos acabam sendo marginalizados pelas particularidades evidenciadas na escrita e pela impossibilidade de atribuírem sentidos aos textos que leem, na lógica solicitada pela escola" (2011, p. 162).

A aplicação de provas diferenciadas (nesse caso, com a vídeo-gravação de vestibulares em Libras) vem ao encontro de tal lacuna vivenciada pelos surdos, que historicamente foram negligenciados (cenário que vem mudando por força de Lei); pela aquisição de linguagem que ocorre em sua maioria tardiamente e que prejudica a aquisição de conceitos mais elaborados e, ainda, pela metodologia oral empregada na maioria das escolas brasileiras, que é incoerente com o canal de comunicação usado pelos surdos para aquisição de língua.

\section{Procedimentos metodológicos}

Apoiado na abordagem histórico-cultural o presente artigo apoia-se na pesquisa de cunho qualitativo, a qual "[...] percebe os sujeitos como históricos, datados, concretos, marcados por uma cultura como criadores de ideias e consciência que, ao produzirem e reproduzirem a realidade social, são ao mesmo tempo produzidos e reproduzidos por ela" (FREITAS, 2002, p. 22).

O método adotado para alcançar os objetivos inicialmente traçados foi o estudo do tipo descritivo e exploratório, pelo qual objetiva-se encontrar o problema, objeto e percurso metodológico, não buscando resolvê-lo, mas, sim, caracterizá-lo. 
O presente estudo foi submetido ao Comitê de Ética da Universidade Federal de Sáo Carlos - Ufscar e pode ser identificado pelo protocolo de código CAAE 33397314.3.0000.5504; foi elaborado e aplicado de acordo com as Diretrizes e Normas Regulamentadoras de Pesquisa Envolvendo Seres Humanos e complementares (Resolução no 466/2012 do Conselho Nacional de Saúde).

\section{Contextualização e sujeitos da pesquisa}

Deslocamo-nos para duas universidades que possuem expertise na tradução e vídeo-gravação de vestibulares em Libras, e são, no momento das entrevistas ${ }^{6}$, as únicas a aplicarem essas provas, a saber: Universidade Federal de Santa Maria (UFSM) e Universidade Federal de Santa Catarina (UFSC).

A UFSM foi a instituição pioneira no Brasil a realizar o vestibular vídeo-gravado em Libras (desde 2010) e findou suas atividades tradutórias em 2015, pois passou a adotar o Exame Nacional do Ensino Médio (Enem) como única forma de acesso à universidade. Nesses anos, a realização da vídeo-gravação foi de responsabilidade da Comissão Permanente do Vestibular (Coperves), que organizou ao todo seis provas vídeo-gravadas em Libras. Em média, cerca de 25.000 mil candidatos (com e sem deficiência) realizaram a prova por ano, com um índice de 3.700 vagas preenchidas anualmente (14,8\% de aprovação). Com relação aos surdos, foram atendidas cerca de 17 pessoas por ano e em média quatro foram aprovados anualmente $(23,5 \%$ de aprovação). Além da vídeo-gravação em Libras, a UFSM conta com cotas, destinando 5\% das vagas a pessoas com "deficiência que lhe traga dificuldade para o desempenho de funçóes educativas na universidade, exigindo atendimento educacional diferenciado" (UFSM, 2014, p. 2), o que favorece o elevado número de surdos aprovados (em proporção superior ao das pessoas sem deficiência).

Na UFSC, o vestibular ocorre desde 2013 e a tradução é realizada pela Comissão Permanente do Vestibular (Coperve), que, ao todo, já realizou três versôes traduzidas do vestibular comum para a Libras. Na UFSC, em média há 34.500 candidatos anualmente, com média de 5.549 aprovados por ano (16,08\% de aprovados). Quanto aos surdos, candidatos aos cursos presenciais da instituição, houve em três anos uma média de quatro inscritos por ano e nenhum aprovado.

A coleta de dados ocorreu por meio de entrevista semiestruturada, conduzida pelo próprio pesquisador, fluente em Libras. Para Manzini, a entrevista (1990/1991, p. 154) "[...] está focalizada em um assunto sobre o qual confeccionamos um roteiro com perguntas principais, complementadas por outras questóes inerentes às circunstâncias momentâneas à entrevista”. O roteiro foi elaborado apoiado na abordagem histórico-cultural, com temas explicativos ou causais, a fim de determinar razóes imediatas ou mediadas pelo social (TRIVIÑOS, 1987). O "roteiro" elaborado é o fio "condutor de algo que se poderia considerar uma "interação antecipada" com o outro que se pretende entrevistar". (ROCHA; DAHER; SANTANA, 2004, p. 177).

Buscamos nas entrevistas a impressáo dos candidatos surdos quanto ao atendimento às suas necessidades linguísticas. Buscou-se criar uma situação que os deixasse à vontade para responder. As entrevistas foram realizadas presencialmente ou via Skype, segundo a disponibilidade dos entrevistados. 
Os sujeitos entrevistados foram surdos que prestaram o vestibular da UFSC e UFSM em formato vídeo-gravado em Libras, no total de 26 participantes: 22 entrevistados candidatos à UFSM (sendo dois via Skype) e quatro à UFSC (todos via Skype). Os surdos serão denominados pela sigla da universidade na qual prestaram o vestibular em Libras, seguida de um número que os diferenciará, de acordo com a ordem das entrevistas, da seguinte forma: o UFSC 01 é o primeiro surdo a ser entrevistado da UFSC; o UFSC 02 é o segundo e, assim, sucessivamente.

Um dado bastante singular em relação aos demais surdos brasileiros é que: 65,3\% dos surdos entrevistados estudaram em escolas bilíngues e 34,7\% concluíram o ensino médio em escolas regulares. Tal diferença deve-se ao fato de que a maioria dos surdos entrevistados é de Santa Maria (RS) e, nesta cidade, há uma escola bilíngue de surdos bastante tradicional, o que os impulsiona para a continuidade dos estudos; já em Florianópolis, todos os surdos entrevistados são de outras regiōes do Brasil com realidades educacionais distintas. Destaca-se, ainda, que nesta capital não há escola de surdos.

\section{Preparação dos dados, análise e interpretação}

Após a realização das entrevistas, transcrevemos todas elas da Libras para a Língua Portuguesa escrita; após a leitura e releitura de todas as transcriçóes é que iniciamos um minucioso trabalho de organização das falas por categorias temáticas, visto que "[...] ao final favorecem reflexão e conhecimento mais aprofundado acerca daquilo que está sendo investigado" (LACERDA, 2003, p. 5). Por sua vez, tais categorias estão relacionadas ao problema de pesquisa inicialmente traçado. Tal método de análise do material buscou apoiar-se na produção de sentidos possíveis na situação discursiva registrada, para alcançar os objetivos inicialmente delineados (LACERDA, 2003).

Após categorizadas todas as falas, buscou-se, por meio do aporte teórico estudado e a partir dos dados coletados nas entrevistas, a interpretação dos temas, focalizando "aspectos descritivos, explicativos e de reflexáo presentes nos depoimentos" (LACERDA, 2003, p. 9). Apresentamos a seguir os resultados e discussóes.

\section{Resultados e discussões: impressões dos candidatos surdos sobre os vestibulares em Libras}

É inegável a preferência dos surdos pelo vestibular vídeo-gravado em Libras, no qual todo o conteúdo é traduzido da Língua Portuguesa escrita para a Libras (com exceção da UFSC, que não traduz as questóes de Língua Portuguesa, e da UFSM, que não realiza a tradução da língua estrangeira - em ambas, a segunda língua é avaliada na própria língua, ou seja, não há traduçóes destas), apontado pelos candidatos como o meio mais eficaz para participação em processos de seleção.

Estando a prova vídeo-gravada em Libras, língua que é acessível aos surdos brasileiros em condiçóes de prestar um vestibular, um dos entrevistados sinaliza que: "A prova em Libras é de suma importância, mais do que em português. Em Libras fica claro o que se pergunta e isso facilita muito. Nas disciplinas de História, Geografia, Ciên- 
cias, Quimica e outras, a tradução é muito importante". (UFSM 10). Fica evidente que a prova vídeo-gravada em Libras é percebida pelo candidato surdo como adequada para sua realização.

Algumas universidades que não oferecem o vestibular em Libras, recorrem a presença do Tradutor e Intérprete de Libras (TILS) para que realize a tradução integral/interpretaçáa ${ }^{7}$ do conteúdo da prova. Porém, os candidatos surdos entrevistados, que já experimentaram outras formas de acesso a outras universidades - sinalizaram que o intérprete "se cansa rápido e, quando se faz a prova em Libras, [o TILS] pode ficar descansando, enquanto assistimos e respondemos às questöes" (UFSM 09).

Outro aspecto apontado pelos surdos em favor da prova vídeo-gravada em Libras é que, com a presença física de um TILS, esse não terá tempo suficiente para realizar a interpretação de todo o conteúdo, pois há vários surdos (geralmente) em uma mesma sala e apenas um intérprete para atender a todos, assim justificam que "se tem na sua sala, por exemplo, 20 surdos inscritos no vestibular, o TILS näo consegue atender de maneira satisfatória a todos; se cada um tem seu computador, assim fica mais fácil". (UFSM 15).

Os motivos que levam os surdos a optar por provas vídeo-gravadas em Libras são diversos e nenhum dos 26 entrevistados prefere a presença física do TILS à vídeogravação, pois afirmam que, com a vídeo-gravação em Libras, eles têm a oportunidade de rever as questóes e as alternativas diversas vezes, na busca de expor da melhor forma possível seu conhecimento. Assim, esclarecem que: "É melhor a vídeo-gravação para a Libras, pois podemos ir e voltar quantas vezes se façam necessárias, até o momento do entendimento da questão; já com o TILS, isso é complicado". (UFSM 14).

Outro fator apontado pelos surdos no que tange à escolha pela prova vídeogravada relaciona-se à possibilidade de fazer uma prova "limpa", ou seja, sem interrupçóes, pois nem sempre o intérprete presente no dia da prova domina todos os conteúdos presentes para a realização de sua interpretação, o que torna o processo de seleção falacioso, pois lhe faltará um arcabouço teórico e lexical para a interpretaçáo, "o que dificulta o entendimento de alguns conhecimentos específicos" (GOULARTE, 2014, p. 35). Com a vídeo-gravação, o ritmo da prova náo é interrompido, nem para leitura dos textos, nem para procurar sinais desconhecidos pelo intérprete ou, ainda, não se fica "perdendo tempo" com a datilologia (recurso de soletração de nomes próprios, sinais não existentes ou ainda, sinais desconhecidos pelos TILS). Assim, sinaliza um dos entrevistados que: "Às vezes com o TILS, pode gerar algumas confusôes na tradução e com o vídeo, não, pois fica mais limpo”. (UFSM 05).

Os surdos entrevistados mostram a necessidade de autonomia para realização do processo, sem ficar na dependência de um TILS, que atende a vários outros surdos e que às vezes não domina determinado conteúdo para sua interpretação de forma clara.

Outra questão tratada pelos entrevistados é a importância da tradução de outras provas para a Libras, como o Enem e outros vestibulares de outras universidades que ainda não contam com a vídeo-gravação: "[...] acho que o maior problema seja a 
falta de tradução para outras provas, como por exemplo, o Enem. Fica muito difícil ler os vários textos e respondê-los, acredito que este sim seja um problema”. (UFSM 07).

Apesar de tantos apontamentos positivos e a exaltação em relação a esse tipo de prova, muitos surdos não alcançaram a aprovação nos vestibulares (na UFSC nenhum surdo até hoje foi aprovado e na UFSM o ingresso de surdos é superior ao de ouvintes - percentualmente) Tal índice se deve ao fato de que muitos surdos não estão acostumados com esse tipo de prova, pois habitualmente foram ensinados e treinados a realizar avaliaçôes em Língua Portuguesa escrita.

Outro apontamento realizado quanto ao fator reprovação no vestibular está ligado ao fato de que as escolas de ensino médio, muitas vezes náo os têm preparado satisfatoriamente para o enfrentamento de uma prova de vestibular, pois alguns deles sinalizaram que as questôes foram difíceis e, assim, tentaram várias vezes o vestibular até conseguirem a aprovação; outros continuam a tentar:

Em 2013 minha maior dificuldade foi na redação e em 2014, eu escrevi um monte, as questôes estavam difíceis, sim, principalmente o Inglês. Acredito que eu preciso estudar mais, para que eu consiga ser aprovado no vestibular, apesar das perguntas terem sido traduzidas para a Libras e eu entendê-las, algumas coisas eu não havia estudado daquele conteúdo e precisava ainda aprendê -las. (UFSM 09).

A redação foi um dos elementos que os surdos mais apontaram para justificar sua reprovação no vestibular, muitos deles sinalizaram que náo entenderam os objetivos do que era para ser dissertado, outros, porém, ainda sinalizaram que escreveram um "monte" e mesmo assim reprovaram. Um candidato esclarece que: "Minha maior dificuldade no vestibular foi na redação, pois perguntamos ao TILS as palavras para que pudéssemos escrever e por questóes éticas eles não podiam nos responder. Tentei o vestibular por duas vezes e reprovei ambas, fiquei traumatizada com a redação e não mais retornei a fazer". (UFSM 05). Tal dificuldade deve-se ao fato de que a incursão dos surdos no mundo da escrita muitas vezes é inviabilizada "por encaminhamentos metodológicos que tomem como ponto de partida a oralidade" (FERNANDES, 2006, p.11), o que gera consequências como as descritas; por isso, ambas as universidades adotam critérios específicos na correção desses textos, amparadas inclusive por legislaçôes que asseguram tal condição.

Todos os surdos foram unânimes nos elogios direcionados aos tradutores da prova, pois a lisura de tal processo depende em muito de quem o faz e "durante a interpretação da prova, os sinais utilizados pelos TILS foram facilmente compreendidos". (UFSC 01). Porém, alguns problemas foram identificados e serão apontados a seguir.

Alguns surdos da UFSM constataram que os movimentos de boca realizados pelos tradutores eram mais evidentes nos tradutores surdos. Explicitam que: "Às vezes eles sinalizavam e falavam ao mesmo tempo, isso atrapalhava muito, pois não sabia se prestava atenção nas mãos ou na boca dos tradutores, eles faziam uso do bimodalismo; isso quem mais fazia eram os professores surdos" (UFSM 17). Cabe indagar se o bimodalis- 
mo apontado por alguns entrevistados é uma movimentação de lábios esperada nas línguas de sinais, ou uma prática simultânea no uso de duas línguas, o que é prejudicial ao entendimento (MARTINS, 2013).

O uso das expressões faciais é de suma importância, pois são traços gramaticais da Libras, que faz diferenciação entre um sinal e outro e, ainda, cumpre o mesmo papel que a entonação da voz nas línguas orais. "No final da vídeo-gravação do vestibular em Libras, senti que os TILS pareciam cansados, com poucas expressóes faciais; no início do vestibular pareciam estar mais animados" (UFSC, 04). A candidata ao vestibular, esclarece que no final da prova sentiu que os tradutores que realizaram a gravaçáo, pareciam estar cansados, porém, como não foi nossa intenção realizar essas observaçóes colhidas diretamente na prova, mas sim, as impressóes dos candidatos, não podemos afirmar se o apontamento realizado por ela procede ou se ela é que estava cansada dada a extensão da vídeo-gravação.

Um último apontamento realizado pelos surdos entrevistados é com relação aos regionalismos e sinais específicos presentes na prova, o que para eles é um fator negativo. Assim aponta um dos entrevistados: "Alguns sinais apresentados no vestibular vídeo-gravado em Libras eu não conhecia, pois moro em São Paulo e eram diferentes do que habitualmente conheço e, assim, os regionalismos complicaram um pouco o entendimento das questóes". (UFSC 04). Os regionalismos presentes na Libras são, assim como no português, as variaçôes que ocorrem a depender da região em que estamos, características da língua, porém, para alguns estudiosos, essas variaçóes são, na verdade, ambiguidades lexicais. (MARTINS; BIDARRA, 2011).

Os sinais específicos a que os surdos se referem na entrevista são aqueles que, devido à especificidade do conteúdo, são desconhecidos por eles, assim como na Língua Portuguesa, em que há palavras específicas de determinadas áreas que não conhecemos, por falta de estudos e leitura de determinado conteúdo.

\section{Considerações finais}

Os vestibulares vídeo-gravados em Libras ainda são escassos no Brasil, pois a maioria das instituiçôes adota o vestibular tradicional (prova impressa em Língua Portuguesa) e oferece aos candidatos com necessidades especiais atendimento diferenciado, como a prova em Braille, ledor, acessibilidade arquitetônica, intérprete de Libras e outros.

Quanto ao intérprete de Libras, não há ainda, no Brasil, nenhuma regulamentação federal quanto à sua atuação nesses processos de seleçáo, sendo que o mesmo pode realizar a interpretação integral da prova, ou apenas a interpretação de palavras, ou, ainda, a interpretação das informaçôes orais que são ditas aos demais candidatos no dia da prova.

Nesse cenário, os surdos têm constantemente se manifestado pelas redes sociais e judicialmente criaram um movimento nacional com o lema "\#ENEMLIBRASJÁ", solicitando a vídeo-gravação do Enem em Libras, imediatamente. 
Ficou nítido nas entrevistas que a vídeo-gravação do vestibular em Libras é uma escolha acertada pelas universidades, haja vista os candidatos a tal prova de vestibular a entenderem como a melhor opção, mais do que a prova em Língua Portuguesa escrita, porém, algumas falhas ainda precisam ser corrigidas, pois como o processo ainda é muito recente, as pesquisas são escassas e com isso faltam aos gestores destas provas as impressóes dos surdos que passaram por tal processo de seleção.

Acreditamos que tais falhas apontadas pelos surdos na vídeo-gravação dos vestibulares podem ser corrigidas com a realização de uma revisão ainda mais sistemática da prova, pormenorizando todos os detalhes apontados, a fim de corrigi-los para que nas próximas ediçôes o processo seja ainda mais eficaz e "limpo".

No entanto, não podemos deixar de explicitar a necessidade de os surdos batalharem por uma educação ainda mais inclusiva e que contemple plenamente suas necessidades (de ter sua língua respeitada e valorada no ambiente escolar) e não somente o suporte no momento de um vestibular.

Pouco adiantará ter um vestibular vídeo-gravado em Libras se os surdos não souberam responder o que se pede - conceitos científicos. É necessário que lutemos por uma educação de qualidade e, tendo esta sido conquistada, o vestibular em Libras será uma opção para os surdos, pois poderão, se quiser, realizar a prova em Língua Portuguesa escrita, haja vista o aprendizado de sua segunda língua de fato ter ocorrido e, ainda, saberá responder às questôes ali postas, pois se apropriou realmente de tais conceitos, o que atualmente é muito questionável, devido à metodologia oralista empregada na maioria das escolas brasileiras.

A realização da vídeo-gravação de provas em Libras no Brasil é muito recente e ainda há muito o que se investigar sobre esse tema. Desejamos, assim, que muitas outras pesquisas possam ser realizadas sobre essa temática, ainda pouco discutida nas universidades, e que os resultados aqui apresentados sejam considerados para a realização de futuros vestibulares vídeo-gravados em Libras.

\section{Referências}

BRASIL. Decreto no 5.626, de 22 de dezembro de 2005. Diário Oficial da União, Poder Executivo, Brasília, DF, 23 dez. 2005. Seçấo I, p. 28. Disponível em: <http://www.planalto. gov.br/ccivil_03/_ato2004-2006/2005/ decreto/d5626.htm>. Acesso em: 05 ago. 2014.

Lei no 10.436, de 24 de abril de 2002. Diário Oficial da Uniáo, Poder Executivo, Brasília, DF, 25 abr. 2002. Seçấo I, p. 23. Disponível em: <http://www.planalto. gov.br/ccivil_03/ LEIS/2002/L10436.htm>. Acesso em: 07 ago. 2014.

Lei no 13.005, de 25 de junho de 2014. Diário Oficial da Uniáo, Poder Executivo, Brasília, DF, 26 jun. 2014. Seçáo I, p. 1. Disponível em: <http://www.planalto. gov.br/ccivil_03/_Ato2011-2014/2014/Lei/L13005. $\mathrm{htm}>$. Acesso em: 12 dez. 2014.

Lei no 13.146, de 06 de julho de 2015. Diário Oficial da Uniáo, Poder Executivo, Brasília, DF, 07 jul. 2015. Seção I, p. 2. Disponível em: <http://www.planalto. gov.br/ccivil_03/_Ato2015-2018/2015/Lei/L13146. htm>. Acesso em: 20 jul. 2015.

Lei no 9.394/96, de 20 de dezembro de 1996. Diretrizes e bases da educaçáo nacional. Diário Oficial da Uniáo, Brasília, DF, 23 dez. 1996. Seção 1, p. 1.

Ministério da Educaçấo. Decreto no 3.284, de 7 de novembro de 2003. Diário Oficial da Uniáo, Brasília, DF, 11 nov. 2003. Seçấo 1, p. 12. Disponível em: <http://portal.mec.gov.br/seesp/arquivos/pdf/port3284. pdf>. Acesso em: 03 ago. 2014. 
BRASIL. Ministério da Educaçấo. Plano Nacional de Educaçáo: Lei no 10.172, de janeiro de 2001. Brasília, 2001.

Ministério da Educação/Gabinete do Ministro. Aviso Circular no 277. Brasília: MEC/GM, 1996. Disponível em: <http://portal.mec.gov.br/seesp/arquivos/pdf/aviso277.pdf>. Acesso em: 05 ago 2014.

Recomendaçáo ${ }^{\circ}$ 001. Brasília: Secretaria Especial dos Direitos Humanos/ Conselho Nacional dos Direitos da Pessoa Portadora de Deficiência, 2010.

MINISTÉRIO DA EDUCAÇÃO. Censo da Educaçáo Superior: 2013. Brasília: MEC/Inep, 2013.

CONSELHO NACIONAL DE SAÚDE (CNS). Resolução n 466, de 12 de dezembro de 2012. Diário Oficial da Uniáo, Brasília, DF, 13 jun. 2013. Seção 1, p. 59. Disponível em: <http://conselho.saude.gov.br/ resolucoes/2012/Reso466.pdf>. Acesso em 28 ago. 2014.

FERNANDES, S. Práticas de letramento na educaçáo bilíngue para surdos. Curitiba: SEED/SUED/DEE, 2006.

FREITAS, M. T. de A. A abordagem sócio-histórica como orientadora da pesquisa qualitativa. Cad. Pesquisa, São Paulo, n. 116, jul. 2002. Disponível em: <http://www.scielo.br/scielo.php? script=sci_arttext\&pi$\mathrm{d}=$ S0100-15742002000200002\&lng=en\&nrm=iso >. Acesso em: 02 fev. 2015.

GOULARTE, R. B. Acesso e permanência no ensino superior: estratégias de governamento da conduta de alunos surdos incluídos. 2014, 107 f. Dissertação (Mestrado em Educação) - Universidade Federal de Santa Maria, Santa Maria, 2014.

LACERDA, C. B. F. A escola inclusiva para surdos: refletindo sobre o intérprete de língua de sinais em sala de aula. 153 f. Roma, 2003. Relatório Científico de Pós-doutorado apresentado à FAPESP. Proc 01/10256-5. 2003.

Surdez e linguagem: implicaçôes. In: MELETTI, S. M. F; KASSAR, M. M. (Org.). Escolarizaçáo de alunos com deficiências: desafios e possibilidades. Campinas: Mercado de Letras, 2013. p.171-202.

MANZINI, E. J. A entrevista na pesquisa social. Didática, São Paulo, v. 26/27, p.149-158, 1990/1991.

MARTINS, T. A. Um estudo descritivo sobre as manifestaçốes de ambiguidade lexical em Libras. 2013. 159 f. Dissertação (Metrado em Letras) - Universidade Estadual do Oeste do Paraná, Cascavel, 2013.

MARTINS, T. A; BIDARRA, J. A ambiguidade lexical em Libras: as dificuldades dos candidatos face ao prolibras. Trama, Cascavel, v. 7, n. 14, p. 135-146, $2^{\circ}$ semestre 2011.

ORGANIZAÇÃO DAS NAÇÓES UNIDAS PARA A EDUCAÇĀO, A CIÊNCIA E A CULTURA (UNES$\mathrm{CO})$. Declaraçáo de Salamanca sobre princípios, política e práticas na área das necessidades educativas especiais. Espanha, Salamanca: Unesco, 1994.

ROCHA, D.; DAHER, M. D. C.; SANT'ANNA, V. L. de A. A entrevista em situaçáo de pesquisa acadêmica: reflexóes numa perspectiva discursiva. Revista Polifonia, Cuiabá, Mato Grosso, v. 8, n. 08, p. 161-180, jul./dez. 2004.

ROCHA, L. R. M. O que dizem surdos e gestores sobre vestibulares em Libras para ingresso em universidades federais. 2015. 125 f. Dissertação (Mestrado em Educação Especial) - Universidade Federal de São Carlos, São Carlos, 2015.

TRIVIÑOS, A. N. S. Introduçáo à pesquisa em ciências sociais: a pesquisa qualitativa em educação. São Paulo: Atlas, 1987.

UNIVERSIDADE FEDERAL DE SANTA CATARINA (UFSC). Edital do Vestibular de 2014. Florianópolis, 2014. Disponível em: <http://www.vestibular2014.ufsc.br/>. Acesso em: 07 mar. 2015.

VYGOTSKY, L. S. A formaçáo social da mente. São Paulo: Martins Fontes, 1984.

\section{Notas}

${ }^{1}$ Neste estudo trazemos os dados do Censo de Educação Superior de 2013 já que os dados dos anos subsequentes ainda estão em alteraçấo/construção.

${ }^{2}$ Surdos: estudantes que utilizavam a Língua de Sinais (surdez severa/profunda) (MEC, 2013).

${ }^{3}$ Deficientes auditivos: estudantes que, por ouvirem pouco, utilizavam, mesmo que precariamente, a modalidade oral da Língua Portuguesa (MEC, 2013). 
${ }^{4} \mathrm{O}$ aviso circular utiliza a nomenclatura "portadores de necessidades especiais", termo usado na época; atualmente em desuso.

${ }^{5}$ Há aqueles que defendem todas as avaliações em Língua de Sinais, o que vai de encontro à legislação, deixando a Língua Portuguesa menos valorizada.

${ }^{6}$ No ano de 2015.

7 Optamos por definir interpretação como a modalidade em que o intérprete de Libras náo tem tempo para pensar sobre suas escolhas, pois não há tempo hábil para, se precisar, realizar consulta e busca por sinais.

${ }^{8}$ Há surdos que estudam na universidade, porém, que não entraram por meio desse processo de seleção vídeo-gravado em Libras, dos cursos presenciais.

\section{Correspondência}

Luiz Renato Martins da Rocha - Universidade Tecnológica Federal do Paraná, Campus Cornélio Procópio. Avenida Alberto Carazzai, 1640, Centro, CEP: 86400-000 - Cornélio Procópio, Paraná - Brasil.

E-mail: renatotils@uenp.edu.br - cristinalacerda@uol.com.br

Recebido em 11 de abril de 2016

Aprovado em 03 de junho de 2016 